\title{
Effect of automatic cluster flushing on the concentration of Staphylococcus aureus in teat cup liners
}

\author{
Alice P. Skarbye, ${ }^{1 *} \odot$ Peter T. Thomsen, ${ }^{1} \odot$ Mogens A. Krogh, ${ }^{1}{ }^{\oplus}$ Line Svennesen, ${ }^{2} \oplus$ and Søren $Ø$ stergaard ${ }^{1} \odot$ \\ ${ }^{1}$ Department of Animal Science, Aarhus University, DK-8830 Tjele, Denmark \\ ${ }^{2}$ Department of Veterinary and Animal Sciences, University of Copenhagen, DK-1870 Frederiksberg C, Denmark
}

\begin{abstract}
Automatic flushing of milking clusters between milking events is a control measure aimed at reducing transmission of mastitis pathogens from infectious milk to a subsequently milked cow. We evaluated the effect of flushing with cold water and flushing with water containing peracetic acid (PAA) on the concentration of Staphylococcus aureus in teat cup liners. Thirty-two clusters in a swing-over milking parlor (Dairymaster, Causeway, Ireland) were subjected to a simulated milking with $S$. aureus-contaminated milk. Sixteen clusters were not flushed (controls), whereas 8 clusters were flushed with cold water $(966 \pm 32 \mathrm{~mL})$ and 8 clusters were flushed with water containing PAA $(200 \mathrm{~mL} /$ $\mathrm{mL}$ ). A random teat cup in each cluster was sampled by rinsing with a phosphate buffer. Teat cup samples were cultured on the day following collection on BairdParker plates to determine the concentration of $S$. aureus. In teat cup samples from control clusters, the mean concentration of $S$. aureus was $2.8 \times 10^{5} \mathrm{cfu} / \mathrm{mL}$. The concentration of $S$. aureus was zero in teat cup samples from clusters flushed with cold water. In teat cup samples from clusters flushed with water containing PAA, the concentration of $S$. aureus was in general reduced compared with control clusters, but $S$. aureus was not removed completely. However, the automatic cluster flushing did not function properly when clusters were flushed with water containing PAA; thus, results reflected the effect of inadequate function rather than the effect of adding disinfectant to the flushing water. Before the main study, we conducted a pilot study to evaluate whether teat cup sampling with swabs and sample analysis with quantitative PCR were appropriate methods for the main study. Specifically, we evaluated the effect of swab sample mass on detection of $S$. aureus by quantitative PCR in the laboratory, Further, we compared PCR and bacterial culture on detection
\end{abstract}

Received October 24, 2019.

Accepted January 27, 2020

*Corresponding author: alice.puk@anis.au.dk of $S$. aureus in a suspension following disinfection of the suspension with PAA. We sampled 20 identical $S$. aureus suspensions for culture and PCR by swabs before and after disinfection with PAA. Swab sample mass was determined by differential weighing and contributed to $46 \%$ of the variation observed in detection of $S$. aureus by PCR. Following disinfection with PAA, S. aureus remained detectable by PCR, although culturability ceased. Based on these results, we sampled teat cups in the main study with a buffer rinse and quantified $S$. aureus in the samples by bacterial culture. We concluded that automatic cluster flushing with cold water was effective in removing $S$. aureus from teat cup liners and that addition of PAA was therefore not necessary. Key words: milking, peracetic acid, polymerase chain reaction, swab

\section{INTRODUCTION}

Mastitis is associated with substantial economic losses (Halasa et al., 2007) and accounts for the majority of antibiotic usage in dairy cattle (Ivemeyer et al., 2011). A key to mastitis control is reduced transmission of pathogens between cows during milking. Cluster cleaning between milking events addresses the risk of transfer of infected milk to a subsequently milked cow. In an early study, cluster pasteurization with $85^{\circ} \mathrm{C}$ water effectively removed culturable bacteria but did not significantly affect the number of new IMI (Neave et al., 1969). Studies on flushing with cold water likewise failed to demonstrate an effect on new IMI, but one had technical issues (Eriksen and Rasmussen, 1994) and the other failed in inducing infections (Schuiling and Neijenhuis, 2005). Flushing with an iodine solution reduced the number of new IMI, but this was limited to Corynebacterium bovis (Smith et al., 1985) and coagulase-positive staphylococci (Hogan et al., 1984). In a German study, flushing with peracetic acid (PAA) reduced the number of new staphylococcal IMI in a herd with a high prevalence of staphylococcal infections (Tenhagen and Heuwieser, 2007). When comparing the mentioned results on cluster cleaning with results on 
teat cleaning and dipping (Galton et al., 1988; Galton, 2004), it seems that cluster cleaning between milking events is less important than teat cleaning and dipping, but is relevant in herds with a high infection level (Tenhagen and Heuwieser, 2007). The development toward larger herds and more automated milking entails a higher ratio of cows to milking units, and in this setting proper cluster cleaning between milking events becomes increasingly relevant.

As studies on the rate of new IMI are both expensive and time consuming, they should be preceded by studies demonstrating a local effect in the cluster. Flushing with cold water is advantageous when considering cost, wear on equipment, and risk of residues in milk. In early reports, flushing with cold water was insufficient in reducing bacterial counts on liners compared with pasteurization or flushing with iodine (Bushnell, 1979; Smith et al., 1985). Older studies on a flushing system using cold water and compressed air reported improved, although variable, results (Shearn et al., 1994; Rasmussen, 1995), whereas a more recent study on flushing in an automatic milking system reported fairly good results (98.4\% reduction) for cold water (Schuiling and Neijenhuis, 2005). The general improvement of results suggests a positive development in the performance of flushing systems over time.

The previous studies on teat cup liners used bacterial culture (BC) to assess the bacterial load of the liners. Ultimately, the detection method should measure the amount of bacteria with intact pathogenicity. Culturability of bacteria is an indicator of high fitness and thus pathogenic potential (Bunthof, 2002). However, environmental samples are complicated by contaminants, creating the need for selective media and serial dilutions. Further, the potential presence of viable but nonculturable mastitis pathogens remains uncertain (Taponen et al., 2009). Quantitative PCR (qPCR) addresses these issues (Keer and Birch, 2003; Taponen et al., 2009), but here a major challenge is the potential detection of nonviable bacteria (Soejima et al., 2012). The detection properties of the qPCR are dependent on the mode of DNA extraction. The Mastit 4 qPCR kit (DNA Diagnostic A/S, Risskov, Denmark) uses a centrifugation step before cell lysis. Theoretically, the qPCR runs on DNA incorporated into denser cell components, improving the chance of detecting viable cells.

The main objective of this study was to evaluate the effect of flushing with cold water and water containing PAA disinfectant on the concentration of Staphylococcus aureus $(\mathrm{cfu} / \mathrm{mL})$ in teat cup liners. To facilitate the choice of sample analysis, the Mastit 4 qPCR was compared with BC on detection of $S$. aureus following disinfection with PAA for 1 min. Further, the variation in sampling mass of FLOQSwabs (Copan Diagnostics
Inc., Brescia, Italy) and the effect of sampling mass on qPCR results were evaluated to facilitate the choice of sampling method.

\section{MATERIALS AND METHODS}

The study consisted of 2 parts: a main study evaluating the effect of flushing of teat cup liners, and a pilot study to aid the choice of sampling method and sample analysis for the main study.

\section{Pilot Study}

The pilot study was conducted as a laboratory study with 20 identical bacterial suspensions. Each suspension was sampled for $\mathrm{BC}$ and $\mathrm{qPCR}$ before and after disinfection with a PAA disinfectant.

Preparing 20 Identical Bacterial Suspensions. An $S$. aureus strain isolated from bovine milk and stored at $-20^{\circ} \mathrm{C}$ was reseeded on a Tryptic soy-based blood agar esculin plate (Eurofins, Vejen, Denmark) and incubated for $16 \mathrm{~h}$ at $37^{\circ} \mathrm{C}$. Five milliliters of brain heart infusion broth (Aarhus University, Foulum, Denmark) was inoculated with colonies from the plate and incubated for $2.5 \mathrm{~h}$ at $37^{\circ} \mathrm{C}$. Subsequently, we transferred 2 $\mu \mathrm{L}$ of the inoculated broth to $90 \mathrm{~mL}$ of peptone water, and the suspension was mixed thoroughly. From this suspension, we made 20 replicas by transferring $1.8 \mathrm{~mL}$ to each of twenty 2-mL Cryotubes (VWR International, Monroeville, PA).

Sampling for Culture and $q P C R$ Before and After Disinfection. From each of the 20 identical suspensions we obtained 2 samples, one for qPCR and one for BC. For $\mathrm{qPCR}$, samples were taken using a 4N6FLOQSwab (cat. no. 4500C, Copan Diagnostics Inc.), a flocked swab with a tip coated with nylon fibers arranged perpendicular on the stick. It comes with an active drying system. When sampling, the swabs were immersed in the suspension for $8 \mathrm{~s}$. We estimated the sample mass taken by the 4N6FLOQSwabs by weighing the cryotubes with content before and after sampling. For BC, we plated $100 \mu \mathrm{L}$ of suspension with a spreader on a blood agar plate (VWR International). All suspensions were vortexed immediately before sampling.

After initial sampling, approximately $1.5 \mathrm{~mL}$ of suspension remained in each tube with some variation due to the inconsistency of swab sample mass. To each tube, we added $300 \mu \mathrm{L}$ of a prepared $3 \%$ solution of a PAA disinfectant (Virodox; Kilco, Dumfries and Galloway, UK), resulting in a final concentration of $0.5 \%$ $(250 \mathrm{~mL} / \mathrm{mL}$ PAA) as recommended by the manufacturer. After addition of PAA, we repeated sampling of each suspension for $\mathrm{qPCR}$ and BC. For the first 10 tubes, disinfection and sampling were carried out for 
one tube at a time. For these, sampling was initiated $60 \mathrm{~s}$ after addition of Virodox. Due to time constrains, the remaining 10 tubes were disinfected simultaneously and then sampled. Using this approach, sampling was done within 30 to $165 \mathrm{~s}$ after addition of PAA. All swab samples were shipped on the same day as collection for analysis at DNA Diagnostic A/S. The Mastit 4 qPCR developed by DNA Diagnostic A/S was used for the analysis. We incubated all agar plates aerobically at $37^{\circ} \mathrm{C}$ and read them after 24 and $48 \mathrm{~h}$, as described by Oliver et al. (2004).

Statistics. The sample size of 20 ensured that in case of an observed specificity for qPCR of $100 \%$ compared with culture, the true specificity would be above $83 \%$ with $95 \%$ certainty based on calculation of the exact confidence interval. We used the statistical software $\mathrm{R}$ version 3.5.0 (R Core Team, 2019) for analyses and graphics. Linear regression was used to assess associations between swab sample mass, culture results, and qPCR results before and after disinfection. Cyclic threshold $(\mathbf{C t})$ values before and after disinfection were separately evaluated as dependent variables of swab sample mass. Cyclic threshold values before disinfection were evaluated as a dependent variable of the concentration $(\mathrm{cfu} / \mathrm{mL})$ of $S$. aureus obtained by culture before disinfection, and $\mathrm{Ct}$ values after disinfection were evaluated as a dependent variable of $\mathrm{Ct}$ values before disinfection. Swab sample mass and culture results were log-transformed for the regressions. The log-transformation supported the theoretically exponential relationship between sample volume and $\mathrm{Ct}$ values, as a doubling in sample volume theoretically gives a 1-unit decrease in the $\mathrm{Ct}$ value. We assessed the assumptions of normality and equal variances by inspection of residual plots. Additionally, we tested the normal distribution of residuals using the Shapiro-Wilk test. Statistical significance was set at $5 \%$.

\section{Main Study}

The main study was carried out on December 10, 2016, in a Danish commercial dairy herd milking with 32 clusters in a swing-over milking parlor (Dairymaster, Causeway, Ireland). Clusters were allocated to 1 of 3 experimental groups: no flushing or disinfection (group A), flushing with cold water (group B), and flushing with cold water containing $0.4 \%$ PAA disinfectant (200 $\mathrm{mL} / \mathrm{mL}$ PAA; group C). All clusters were subjected to a simulated milking with $S$. aureus-contaminated milk. Subsequently, clusters were flushed according to their experimental group and then teat cups were sampled for BC.

Initial Status of Clusters. We conducted the study between the morning (0600-0900 h) and after- noon (1400-1700 h) milkings in the herd. The teat cup liners had been replaced 1 mo before the study was conducted and had been used for approximately 1,000 milking events each. Before initiation of the study, cleaning of the milking system was carried out.

Cluster Allocation into Experimental Groups. The 32 milking clusters were paired into 16 cluster pairs. In each pair, 1 cluster was allocated to group A. In the odd-numbered pairs, the remaining cluster was allocated to group B, and in the even-numbered pairs, the remaining cluster was allocated to group C. Sixteen clusters were allocated to group A, whereas 8 clusters were allocated to B and 8 clusters were allocated to C.

Teat Cup Sampling Procedure. Teat cups were sampled following a modified version of the protocol described by Smith et al. (1985). Sterile 50-mL centrifugal tubes were supplied with $20 \mathrm{~mL}$ of sterile PBS each and autoclaved. We closed the short milk hose of the teat cup chosen for sampling using a clamp. Then, we transferred the $20 \mathrm{~mL}$ of PBS from the centrifugal tube to the teat cup by inserting the opening of the tube into the mouthpiece of the teat cup. We tilted the teat cup with the tube still attached back and forth 5 times before we transferred the PBS back into the tube, which was then detached from the mouthpiece.

S. aureus-Contaminated Milk. In the laboratory, $200 \mathrm{~mL}$ of brain heart infusion broth was inoculated with bovine $S$. aureus and incubated at $37^{\circ} \mathrm{C}$ overnight. The following morning, the concentrated $S$. aureus inoculant (approximately $10^{8-9} \mathrm{cfu} / \mathrm{mL}$ ) was transported on ice to the study herd. At the morning milking in the study herd on the day of the study, $200 \mathrm{~kg}$ of milk was separated into a calf milk pasteurizer, which was programmed for pasteurizing the milk and keeping it at $42^{\circ} \mathrm{C}$ afterward. We made the contaminated milk by weighing $10 \mathrm{~kg}$ of the pasteurized milk into a clean bucket and adding $10 \mathrm{~mL}$ of the concentrated S. aureus inoculant. One bucket of contaminated milk was prepared for each cluster pair. To determine the final concentration of $S$. aureus in the contaminated milk, we took a sample from each bucket using a sterile syringe.

Simulated Milking. Each milking cluster was subjected to a simulated milking using a phantom udder and $S$. aureus-contaminated milk. We had constructed 2 phantom udders for this purpose. A phantom udder consisted of 4 teat cup blockers and 4 plastic tubes. We drilled a hole $(5 \mathrm{~mm})$ in the center of each blocker and inserted the end of a plastic tube $(5 \mathrm{~mm} \times 1 \mathrm{~m})$ into each hole. We attached each of the 2 phantom udders to a cluster in a cluster pair. Then, we inserted the free plastic tube ends of both phantom udders into the $S$. aureus-contaminated milk in the bucket and started milking. Hereby, the 2 clusters in each cluster pair were subjected to simulated milkings simultaneously using 
the same $10 \mathrm{~kg}$ of milk. We registered the milking time for 3 randomly chosen cluster pairs $(2,5$, and 8$)$.

Flushing Procedure. Following the simulated milking, the clusters allocated to groups $\mathrm{B}$ and $\mathrm{C}$ were flushed automatically. The flush consisted of 2 flushes with water followed by an air purge. In group C, water containing PAA was used for the second water flush. The flush lasted less than 10 s. After flushing, we sampled 1 randomly chosen teat cup in each cluster to assess the bacterial concentration in the liner. For all clusters in groups B and C, the flushing was tested before experimentation was started. We collected the flushing water at cluster level and determined the volume. At testing of the flushing volumes, we observed that the flush on the last cluster (cluster 32) was deactivated. This was activated, and we started experimentation on group $\mathrm{C}$ cluster pairs. However, during experimentation we noted that the flush was not functioning properly anymore, as the water pressure was reduced. We deactivated the flush on cluster 32 again, thus restoring the functioning of the flush. Due to these technical problems, the flush did not work properly at experimentation on 5 cluster pairs (pairs 2, 4, 6, 8, and 10). Thus, during experimentation the flush functioned correctly in all of the 8 cluster pairs allocated to testing flush with water but in only 3 of the 8 cluster pairs allocated to testing flush with water containing PAA.

Samples to Test for Initial Contamination. Following the initial system cleaning, we sampled 1 teat cup liner in each of 4 randomly chosen clusters $(1,6$, 17, and 28) to determine the total bacterial count and thus assess the initial contamination level of the liners. Additionally, we took a sample from the pasteurized milk through the tab in the bottom of the pasteurizer and a sample of the flush water from the water inlet.

Bacterial Culture. Samples were stored at $5{ }^{\circ} \mathrm{C}$ until plating for BC. We plated all samples on the day following collection (T2). Additionally, we plated a subset of samples (milk and teat cup samples from cluster pairs 1-6) on the day of collection (T1) to assess the effect of storage.

Before culturing, we acclimatized and homogenized the samples on a vortex mixer for $10 \mathrm{~s}$. Subsequently, $100 \mu \mathrm{L}$ was pipetted onto an agar plate and spread out using a cell spreader. We constructed dilutions in peptone water and plated these as well. The choice of agar and the number of dilutions were dependent on the type of sample. We incubated all plates at $37^{\circ} \mathrm{C}$ and read them at approximately $24 \mathrm{~h}$ from plating.

We plated the 6 samples taken to assess initial contamination (4 from teat cup liners, 1 from pasteurized milk, 1 from water inlet) on blood agar (VWR International), and dilutions of $10^{-1}, 10^{-2}$, and $10^{-3}$ were made and plated on blood agar. Likewise, we plated the 16 samples taken from the buckets of contaminated milk on blood agar. For these, higher dilutions were made $\left(10^{-3}, 10^{-4}\right.$, and $\left.10^{-5}\right)$ as we expected them to have higher concentrations. We plated the 32 teat cup samples on Baird-Parker agar (VWR International), and dilutions of $10^{-1}, 10^{-2}, 10^{-3}, 10^{-4}$, and $10^{-5}$ were made and plated. We used the selective Baird-Parker plates to facilitate detection of $S$. aureus in case contaminants were present.

Statistics. The milking system with 32 milking clusters allowed for 8 clusters in each experimental group. This was sufficient to demonstrate a difference in means on a level as reported previously for the Airwash system (0.77 log reduction; Shearn et al., 1994) assuming a standard deviation of $0.5 \mathrm{log}$ units. We used dilutions with a colony count of between 25 and 300 to calculate colony-forming units per milliliter. Statistical software R 3.5.0 (R Core Team, 2019) was used for analyses and graphics. Paired $t$-test was used to evaluate differences between the samples cultured at $\mathrm{T} 1$ and T2. The samples from the contaminated milk and the teat cups were analyzed separately. We assessed distributional normality of the differences by normal quantile-quantile plots. Additionally, we calculated the power for the 2-sided paired test on teat cup samples. Statistical significance was set at $5 \%$.

\section{RESULTS}

\section{Pilot Study}

Culture Results. Cultures of samples taken from the 20 suspensions before disinfection all showed pureculture growth with delta-hemolytic colonies morphologically similar to the $S$. aureus used. We counted colony-forming units on each plate manually, and the mean concentration in the 20 suspensions before disinfection was $9,040 \mathrm{cfu} / \mathrm{mL}( \pm 120$; minimum $=8,300$; maximum $=9,910)$. Cultures of the 20 samples taken after disinfection showed no signs of growth at 24 or $48 \mathrm{~h}$.

$q P C R$ Results. The mean $\mathrm{Ct}$ value obtained by qPCR for the 20 samples taken before disinfection was $24.07( \pm 0.32 ;$ minimum $=20.96$, maximum $=26.29)$. After disinfection, the mean $\mathrm{Ct}$ value of the 20 samples was $27.40( \pm 0.09$; minimum $=26.49$, maximum $=28.30)$, corresponding to a mean increase of 3.33 $( \pm 0.34)$.

Swab Sample Mass. We acquired swab sample mass estimates for 38 swab samples with a mean of $224 \mathrm{mg}( \pm 2.8 ;$ minimum $=192$, maximum $=272)$ and a standard deviation of $17 \mathrm{mg}$. The coefficient of varia- 
tion was thus $8 \%$. The $\mathrm{Ct}$ values obtained before disinfection decreased with increasing swab sample mass $\left(F_{1,17}=14.7, P=0.001\right.$; Figure 1a). The coefficient of determination for the relation was 0.46 . The $\mathrm{Ct}$ values obtained before disinfection were not statistically associated with concentrations obtained by culture $\left(F_{1,18}=\right.$ $0.05, P=0.82$; Figure $1 \mathrm{~d})$. The $\mathrm{Ct}$ values obtained after disinfection were not associated with either sample mass $\left(F_{1,16}=0.23, P=0.64\right)$ or $\mathrm{Ct}$ values obtained before disinfection $\left(F_{1,18}=0.03, P=0.87\right.$; Figure $1 \mathrm{~b}$ and $\mathrm{c})$.

\section{Main Study}

Initial Contamination. Culture of the sample of pasteurized milk showed growth of 2 morphologically different bacteria. The predominating colonies $(2.3 \times$ $10^{4} \mathrm{cfu} / \mathrm{mL}$ ) were small, gram positive, and catalase negative, with esculin hydrolysis and Turkish blue coloring on chrome agar suggestive of Streptococcus uberis. Larger gram-positive and catalase-positive colonies forming gray colonies on Vogel-Johnson agar with purple coloring of the medium (suggestive of CNS) were a)

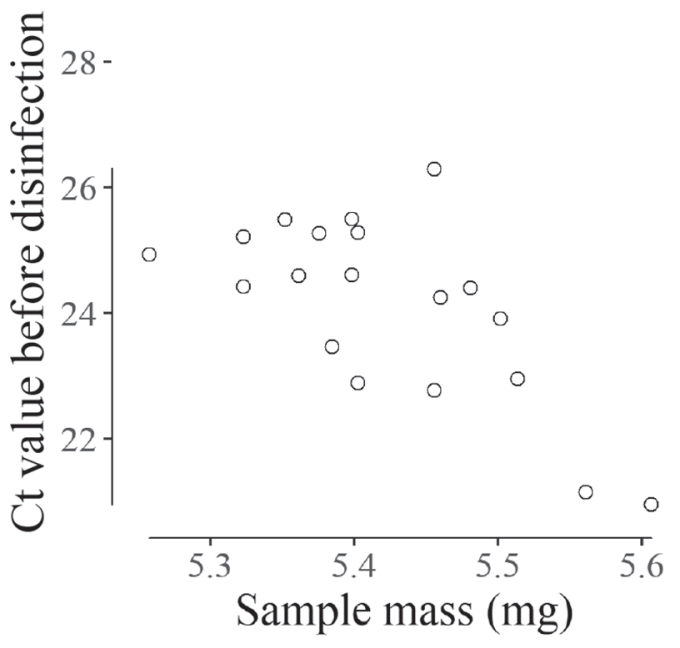

c)

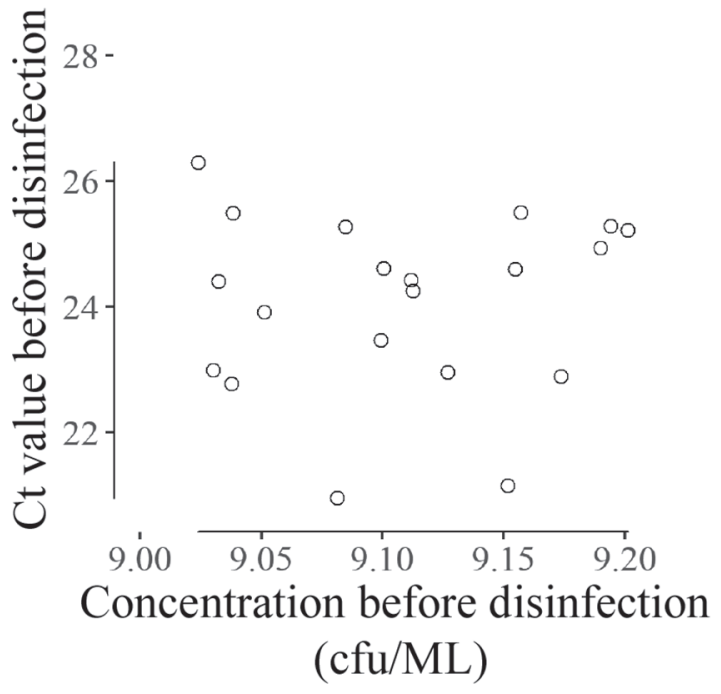

b)

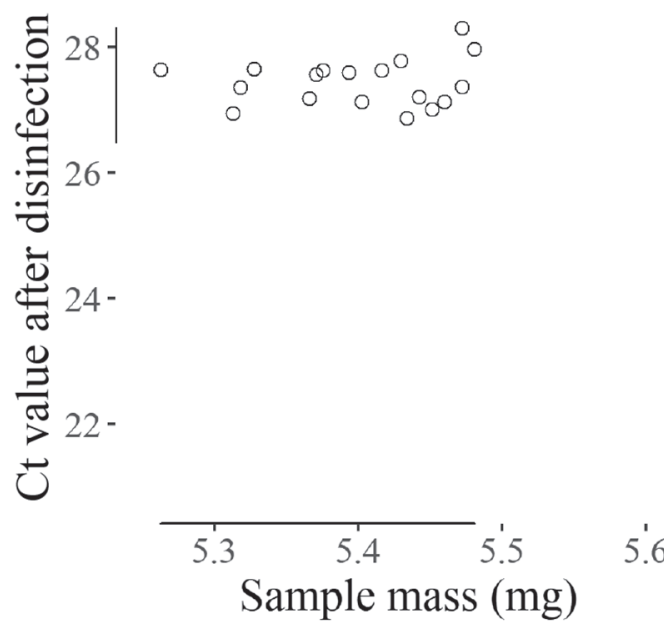

d)

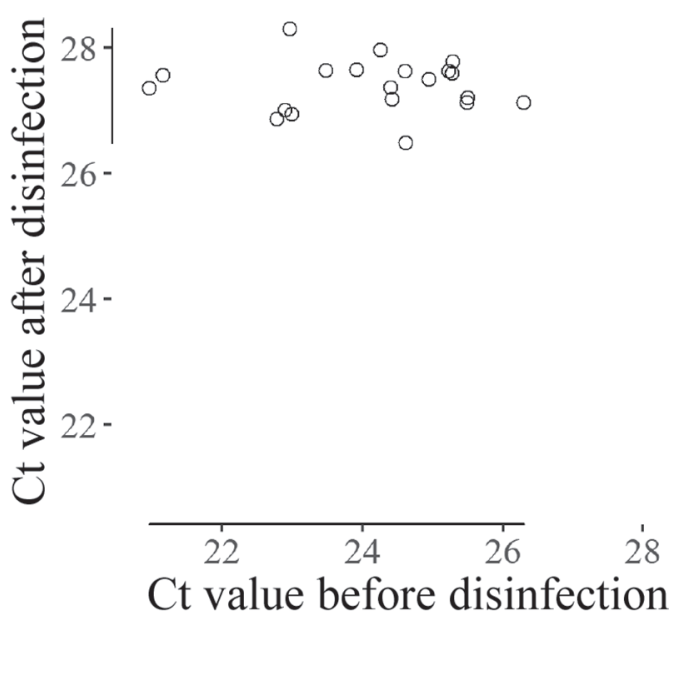

Figure 1. Range frame scatterplots of cyclic threshold (Ct) values for Staphylococcus aureus (a) before and (b) after disinfection with peracetic acid against swab sample mass $(\mathrm{mg})$. (c) Range frame scatterplot of $\mathrm{Ct}$ values for $S$. aureus before disinfection against concentration (cfu/ $\mathrm{mL}$ ) of $S$. aureus before disinfection. (d) Range frame scatterplot of $\mathrm{Ct}$ values for $S$. aureus after disinfection against Ct values before disinfection. Swab sample mass and concentration $(\mathrm{cfu} / \mathrm{mL})$ are plotted logarithmic. Broken axes reflect the range frame aspect of the scatterplots. 
present in lower concentration $\left(1.4 \times 10^{4} \mathrm{cfu} / \mathrm{mL}\right)$. The total bacterial count in the 4 teat cup samples taken before the simulated milking was $0,70,60$, and $40 \mathrm{cfu} /$ $\mathrm{mL}$, respectively.

Flushing Water and Volume. No growth was observed at culturing of water from the inlet to the flushing system. The mean volume of water used for flushing was $966 \mathrm{~mL}( \pm 32 \mathrm{~mL})$ when flushing was tested before study start.

Milk Samples. The mean concentration of S. aureus in the contaminated milk used for simulated milking was $8.3 \times 10^{5} \mathrm{cfu} / \mathrm{mL}$ with a standard deviation of 2.6 $\times 10^{5} \mathrm{cfu} / \mathrm{mL}$. Milking time of the simulated milking was noted for 3 random cluster pairs as 53,59 , and 63 $\mathrm{s}$, corresponding to a mean flow rate of $5.1 \mathrm{~kg} / \mathrm{min}$.

Teat Cup Samples. Figure 2 shows BC results for the teat cup samples at T2. The mean concentration of $S$. aureus in samples taken from non-flushed teat cup liners (group A) was $2.8 \times 10^{5} \mathrm{cfu} / \mathrm{mL}$ with a standard deviation of $0.8 \times 10^{5} \mathrm{cfu} / \mathrm{mL}$. Teat cup samples taken from clusters subjected to flushing with water (group B) showed no growth of $S$. aureus. Similarly, teat cup samples from 4 of the clusters subjected to flushing with PAA (group C) showed no growth of $S$. aureus. In the remaining 4 clusters in group $\mathrm{C}$, a mean concentration of $3.2 \times 10^{4} \mathrm{cfu} / \mathrm{mL}$ was detected with a standard

- Flushed Teat Cup $\oplus$ Non-flushed Teat Cup

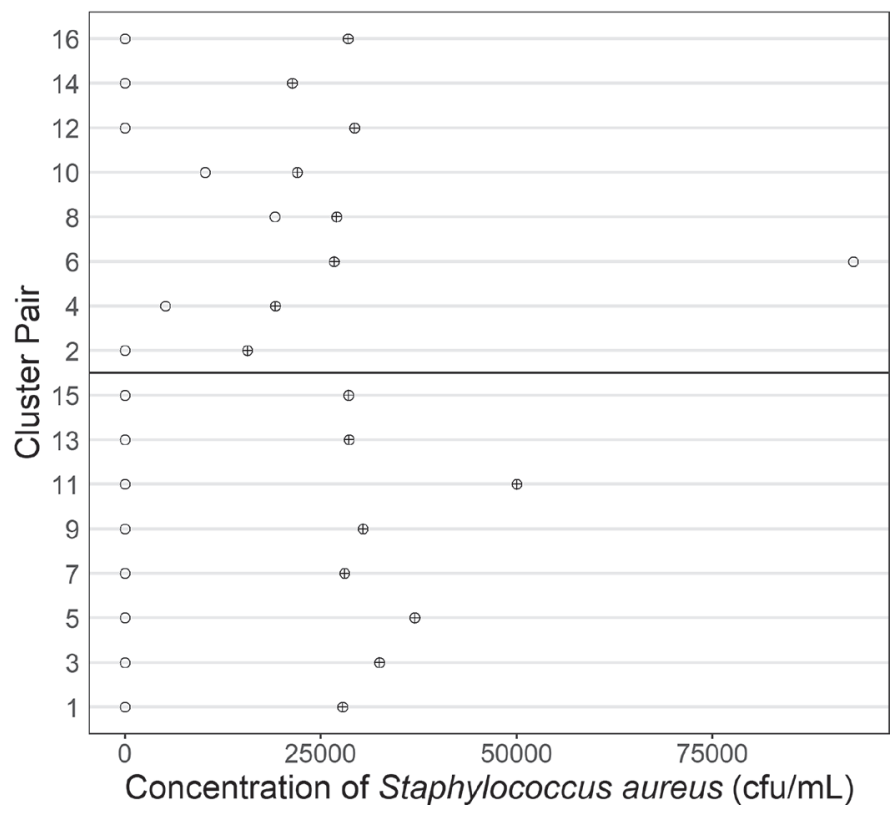

Figure 2. Concentration of Staphylococcus aureus (cfu/mL) recovered from non-flushed and flushed teat cup liners. For the lower half, clusters were flushed with cold water. For the upper half, clusters were flushed with cold water containing peracetic acid. deviation of $4.1 \times 10^{4} \mathrm{cfu} / \mathrm{mL}$. The large standard deviation resulted from a very high concentration in cluster $12\left(9.3 \times 10^{4} \mathrm{cfu} / \mathrm{mL}\right)$.

Repeated Cultures at T1 and T2. Six samples of $S$. aureus-contaminated milk (used for simulated milking in cluster pairs 1-6) were cultured at both T1 and T2. For these a mean increase of $1.4 \times 10^{5} \mathrm{cfu} / \mathrm{mL}$ was observed (paired $t$-test, $t_{5}=-2.67, P=0.04$ ). Six teat cup samples in group A were cultured at T1 and T2. The detection on Baird-Parker agar was decreased by $1.5 \times 10^{4} \mathrm{cfu} / \mathrm{mL}\left(\mathrm{SD}: 2.0 \times 10^{4} \mathrm{cfu} / \mathrm{mL}\right)$ at $\mathrm{T} 2$ compared with $\mathrm{T} 1$, but this difference was not significant (paired $t$-test, $t_{5}=1.85, P=0.12$ ). The statistical power of the test was 0.32 for the 6 sample pairs. Three teat cup samples in group B were cultured at both T1 and T2. Staphylococcus aureus was not recovered at T2. However, at T1, 1 of the 3 samples displayed growth (50 $\mathrm{cfu} / \mathrm{mL}$ ). Similarly, 3 teat cup samples in group $\mathrm{C}$ were cultured at both T1 and T2. For 1 of these samples, $S$. aureus was not detected at either time, whereas $S$. aureus was recovered from the other 2 samples (cluster 8 and 12) at both time points. For cluster 12, detection increased from $2.8 \times 10^{4} \mathrm{cfu} / \mathrm{mL}$ at $\mathrm{T} 1$ to $9.3 \times 10^{4}$ $\mathrm{cfu} / \mathrm{mL}$ at $\mathrm{T} 2$, whereas detection decreased for cluster 8 from $8.2 \times 10^{3}$ at $\mathrm{T} 1$ to $5.1 \times 10^{3} \mathrm{cfu} / \mathrm{mL}$ at $\mathrm{T} 2$.

\section{DISCUSSION}

Our results show that automatic flushing with cold water was sufficient to remove all $S$. aureus from the teat cup liners when considering results obtained by BC at T2. In previous studies, reductions in total bacterial count of $61 \%$ (Shearn et al., 1994) and 88\% (Rasmussen, 1995) were observed for flushing with cold water in the Airwash system, whereas the reduction for $S$. aureus was $46 \%$ (Rasmussen, 1995). For flushing with cold water in an automatic milking unit, a higher reduction of $98.4 \%$ was reported for Streptococcus agalactiae (Schuiling and Neijenhuis, 2005). The flushing volume $(966 \mathrm{~mL})$ in the present study exceeded those reported for the Airwash system (750 mL; Rasmussen, 1995) and for automatic milking systems (500 mL; Jensen, 2009). This presumably explains the more efficient removal of $S$. aureus by automatic flushing in the present study compared with previous reports. Our results for flushing with water plus PAA reflect that the flush did not function properly at experimentation on cluster pairs $2,4,6,8$, and 10 . It is thus not possible to evaluate the effect of PAA from these. Instead, the results underline the importance of continual control of the flush functioning, as substantial amounts of $S$. aureus were recovered from the affected clusters. Assuming that water is sufficient to remove all bacteria, there is no additional 
benefit of adding PAA to the flush water. This is in agreement with the previous studies comparing flushing with pure water and water plus disinfectants (Shearn et al., 1994; Schuiling and Neijenhuis, 2005).

The results comparing $\mathrm{BC}$ of teat cup samples at $\mathrm{T} 1$ and T2 raise concern that detection of $S$. aureus was reduced by storing the teat cup samples overnight. The decreased detection of $S$. aureus in group A clusters at T2 compared with T1 was not significant, but the test had low power (0.32). Additionally, 2 of the 6 samples cultured at T1 and T2 obtained from group B and $\mathrm{C}$ clusters displayed the same pattern. Evidently, culturing the same day as sample collection is preferable. In the sample with no growth observed at $\mathrm{T} 2$, the concentration observed at $\mathrm{T} 1$ was comparable with that observed in the teat cups following system cleaning of the milking plant. Thus, we suspect that at BC on the same day as sample collection the $S$. aureus concentrations would reflect those observed following system cleaning. Removal of this residue presumably requires extensive cleaning beyond what is practically possible without prolonging the milking work routine. The importance of the remaining bacterial load is uncertain and can only be assessed by studies on the effect on new infections.

To evaluate the economic value of an automatic flushing system, it is essential to clarify how the reduction in bacterial load in the teat cup liners affects the transmission of mastitis pathogens. As indicated by previous studies, this depends on the within-herd infection level (Tenhagen and Heuwieser, 2007). Additional considerations include the effect on work time and wear on equipment. Automatic cluster hygiene is time saving compared with manual hygiene (Ohnstad et al., 2012), and farmers in general find that additional time requirements are limited (Pocknee, 2010). Another determinant of costs is the flushing volume. A large flushing volume may be more effective but adds to the costs, and if too much water is retained in the milking system, it may affect the freezing point of the milk (Hanus et al., 2015).

To evaluate the effect of automatic flushing on the bacterial load in teat cup liners, we needed to collect and analyze environmental samples from the teat cups. The majority of previous studies have used swabs to collect samples, and all studies have used BC to assess the bacterial load of the samples. We had some considerations with respect to swab sampling and BC and thus performed the pilot study to address these.

Our primary concern with swab sampling was that the technique is sensitive to variation in pressure applied during sampling, size of sampled surface, surface contact time, and swab absorbency. In the laboratory, we were able to sample with identical contact surface and contact time when using the FLOQSwabs. By this, we observed that the sample mass variation due to absorbency was low (8\%). However, despite the limited variation, it accounted for $46 \%$ of the variation observed in Ct values before disinfection. It is noteworthy that $\mathrm{Ct}$ values obtained before disinfection were not associated with concentrations of $S$. aureus obtained by culture. This is presumably due to the low variation in the concentrations and supports the idea that the variation in $\mathrm{Ct}$ values is procedure related. At sampling with swabs in the field, we would expect greater variation due to the procedure and thus a greater effect on bacterial recovery. A recent study confirms a considerable effect of swab sampling procedure on efficiency of microbial recovery (You et al., 2019).

A few studies on bacterial load in teat cup liners have sampled using a phosphate buffer rinse of the teat cup (Smith et al., 1985; Eriksen and Rasmussen, 1994). The advantage of this technique is that the entire surface of the liner is sampled and the potential variation in application pressure is limited. We chose this sampling technique for the main study to minimize the effect of sampling procedure on bacterial recovery. The concentrations of $S$. aureus in teat cup samples were considerably lower than those of the contaminated milk, as the buffer diluted the sampled milk residues. It is noteworthy that the buffer rinse sampling method recovers only nonadhesive content from the teat cup liners. Thus, this method evaluates the ability of the flush to remove nonadhesive content from the teat cups and does not extend to bacterial load attached in, for instance, biofilm. The purpose of automatic flushing between milking events is to remove milk that was recently added from the preceding cow. Thus, it is appropriate that the method evaluates the effect on nonadherent bacteria. For investigations of the effect on adherent bacteria, a thorough brushing of the teat cup liner during a buffer rinse could be considered.

When analyzing environmental samples with BC, it is necessary to consider appropriate selective media and dilutions to deal with potential contaminants and overgrown plates. To avoid these issues, we considered using qPCR because it directly quantifies the bacteria of interest regardless of contaminants and concentrations. Automatic flushing with cold water removes bacteria from the teat cup liners and does not affect the viability of the bacteria. Thus, it is feasible to assess the effect of flushing with cold water by using qPCR for sample analysis. Contrarily, flushing with water containing PAA is expected to affect the viability of the bacteria.

In the laboratory, we evaluated how the effect on viability by PAA disinfection affected culturability and 
qPCR detectability of the bovine $S$. aureus we wanted to use in the main study. Following disinfection with PAA in the laboratory, $S$. aureus was not detected by BC. However, $S$. aureus remained detectable by Mastit $4 \mathrm{qPCR}$. The Ct values obtained after disinfection were higher than before disinfection, and the mean difference corresponded to the final concentration of DNA being one-eighth of the start concentration. However, the $\mathrm{Ct}$ values obtained following disinfection are associated with a high amount of detected DNA. In 10 samples, the action time of PAA was $60 \mathrm{~s}$, whereas it varied from 30 to $165 \mathrm{~s}$ for the remaining 10 samples. The variation in action time may have influenced the results obtained following disinfection. However, there is no indication of this in either culture or qPCR results, as all cultures were negative and $\mathrm{qPCR}$ results showed very little variation reflected in the low standard error ( $\pm 0.09 \mathrm{Ct}$ value).

The disinfection property of PAA results from oxidations and formation of free radicals causing disruption of membrane integrity and potential and inducing protein and nucleic acid damage (Fröhling et al., 2010; Wessels and Ingmer, 2013). Our results indicate that the membrane damage induced by PAA is limited because there is still some nucleic acid enclosed in denser cell components. This is in agreement with a previous flow cytometry study suggesting that permeabilization of cell membranes is incomplete after 2 min of treatment with PAA (Fröhling and Schlüter, 2015). The flow cytometry evaluation also showed that some metabolic activity remains after 2 min of treatment with PAA, raising the question of the viability of the intact cells (Fröhling and Schlüter, 2015).

The Ct values obtained before disinfection showed dependency on swab sampling mass. On the contrary, $\mathrm{Ct}$ values observed after disinfection showed little variation and were not associated with either $\mathrm{Ct}$ values before disinfection or swab sample mass. This suggests that PAA did not cause a linear decrease in the concentration of nucleic acids but instead caused a decrease to a specific level. The reason for this is unclear but may reflect some aspect of how PAA affects the bacteria. Due to the continued uncertainty about the viability of qPCR-detectable bacteria, we chose BC for analysis of teat cup samples in the main study.

Despite the recent system cleaning of the milking clusters in the study herd, there was some initial contamination in 3 out of 4 tested teat cups. However, the concentrations of bacteria were insufficient to influence the experiment. The contaminants from the pasteurized milk were not observed in the milk used for simulated milking as their concentrations likewise were below the detection limit of the dilution series. Further, the water used for flushing was sterile, thus not contributing any bacteria to the experiment. The $S$. aureus concentration in milk used for simulated milking reflected concentrations observed in cows with a high infection level (Schuiling and Neijenhuis, 2005). The flow rate during simulated milking was relatively high but did not exceed that observed for natural milking events (Hogeveen et al., 2001). The milk volume and milking time for the simulated milking were lower than those of a natural milking event, but we do not expect an influence on milk coverage of and adhesion to the liner from this difference. The simulated milking thus reflects conditions of a natural milking of an infected cow to a degree where we expect that the efficient removal of $S$. aureus from teat cup liners by automatic cluster flushing can be extended to natural milking events.

\section{CONCLUSIONS}

Automatic cluster flushing with $966 \mathrm{~mL}$ of cold water removed all $S$. aureus from teat cup liners subjected to simulated milking with $S$. aureus-contaminated milk. Addition of PAA is unnecessary because water without PAA was sufficient to remove all bacteria. However, as detection of $S$. aureus from teat cup samples decreased at storage overnight, the effect should preferably be evaluated by BC on the same day as sample collection. In the laboratory, $S$. aureus remained detectable by Mastit $4 \mathrm{qPCR}$ following disinfection with PAA, although we observed no growth at BC. As the viability and thus pathogenicity of the qPCR-detectable $S$. aureus is unknown, Mastit $4 \mathrm{qPCR}$ is not feasible for analysis of environmental samples subjected to PAA. In the laboratory, we further observed that despite a limited variation in FLOQSwab sample mass, it accounted for $46 \%$ of the variation in $\mathrm{Ct}$ values obtained by qPCR for the swab samples. A considerable effect of the swab sampling procedure on bacterial recovery from environmental surfaces should therefore be expected. It is thus relevant to consider alternative methods when sampling environmental surfaces.

\section{ACKNOWLEDGMENTS}

The Danish Milk Levy Fund (Aarhus, Denmark) funded the project through the grant "Effective control of contagious mastitis - STOPMAST." DNA Diagnostic A/S (Risskov, Denmark) sponsored and carried out the Mastit 4 quantitative qPCR analysis for the pilot study. Conducting the study depended entirely on the efforts of dedicated technicians and the hospitality of the study herd owner. The authors have no conflicts of interest. 


\section{REFERENCES}

Bunthof, C. J. 2002. Flow cytometry, fluorescent probes, and flashing bacteria. PhD Thesis. Department of Food Sciences and Agrotechnology, Wageningen University, Wageningen, the Netherlands.

Bushnell, R. B. 1979. Backflushing-Next step in automation. Dairy Herd Manage. 16:66-72.

Eriksen, L., and M. D. Rasmussen. 1994. Automatic backflushing of teatcup liners by the Airwash system. Research report 25. Research on Cattle and Sheep, National Institute of Animal Science, Foulum, Denmark.

Fröhling, A., and O. Schlüter. 2015. Flow cytometric evaluation of physico-chemical impact on Gram-positive and Gram-negative bacteria. Front. Microbiol. 6:939. https://doi.org/10.3389/fmicb .2015.00939.

Fröhling, A., M. Wienke, S. Rose-Meierhöfer, and O. Schlüter. 2010. Improved method for mastitis detection and evaluation of disinfectant efficiency during milking process. Food Bioprocess Technol. 3:892-900. https://doi.org/10.1007/s11947-010-0366-9.

Galton, D. M. 2004. Effects of an automatic postmilking teat dipping system on new intramammary infections and iodine in milk. J. Dairy Sci. 87:225-231. https://doi.org/10.3168/jds.S0022 -0302(04)73161-6.

Galton, D. M., L. G. Peterson, and W. G. Merrill. 1988. Evaluation of udder preparations on intramammary infections. J. Dairy Sci. 71:1417-1421. https://doi.org/10.3168/jds.S0022-0302(88)79700 -3 .

Halasa, T., K. Huijps, O. Osteras, and H. Hogeveen. 2007. Economic effects of bovine mastitis and mastitis management: A review. Vet. Q. 29:18-31. https://doi.org/10.1080/01652176.2007.9695224.

Hanus, O., M. Tomaska, M. Hofericova, M. Vyletelova-Klimesova, L. Klapacova, R. Jedelska, and M. Kolosta. 2015. Relationship between freezing point and raw ewes' milk components as a possible tool for estimation of milk adulteration with added water. J. Food Nutr. Res. 54:281-288.

Hogan, J. S., R. J. Harmon, B. E. Langlois, R. W. Hemken, and W. L. Crist. 1984. Efficacy of an iodine backflush for preventing new intramammary infections. J. Dairy Sci. 67:1850-1859. https://doi .org/10.3168/jds.S0022-0302(84)81513-1.

Hogeveen, H., W. Ouweltjes, C. de Koning, and K. Stelwagen. 2001. Milking interval, milk production and milk flow-rate in an automatic milking system. Livest. Prod. Sci. 72:157-167. https://doi .org/10.1016/S0301-6226(01)00276-7.

Ivemeyer, S., G. Smolders, J. Brinkmann, E. Gratzer, B. Hansen, B. I. F. Henriksen, J. Huber, C. Leeb, S. March, C. Mejdell, S. Roderick, E. Stoger, M. Vaarst, L. K. Whistance, C. Winckler, and M. Walkenhorst. 2011. Effects of health and welfare planning on the use of antibiotics and udder health in European dairy farms. Pages 69-76 in Udder Health and Communication. H. Hogeveen and T. J. G. M. Lam, ed. Wageningen Acad. Publ., Wageningen, the Netherlands.

Jensen, M. L. 2009. Power and water consumption with AMS. Accessed Dec. 16, 2019. https://www.landbrugsinfo.dk/Tvaerfaglige -emner/FarmTest/Filer/Farmtest61-AMS-UK-web.pdf.

Keer, J. T., and L. Birch. 2003. Molecular methods for the assessment of bacterial viability. J. Microbiol. Methods 53:175-183. https:// doi.org/10.1016/s0167-7012(03)00025-3.

Neave, F. K., F. H. Dodd, R. G. Kingwill, and D. R. Westgarth. 1969. Control of mastitis in dairy herd by hygiene and management. J. Dairy Sci. 52:696-707. https://doi.org/10.3168/jds.S0022 -0302(69)86632-4.

Ohnstad, I., R. G. M. Olde Riekerink, P. Hogewerf, C. A. J. M. de Koning, and H. W. Barkema. 2012. Short communication: Effect of automatic postmilking teat disinfection and cluster flushing on the milking work routine. J. Dairy Sci. 95:2567-2570. https://doi .org/10.3168/jds.2011-4946.

Oliver, S., R. Gonzalez, J. Hogan, B. Jayarao, and W. Owens. 2004 Microbiological procedures for the diagnosis of bovine udder infection and determination of milk quality. National Mastitis Council, Verona, WI.

Pocknee, B., and P. Chatterton. 2010. Assessing milking cluster hygiene value. Pages 99-100 in Proc. British Mastitis Conference, Worcester, UK. The Dairy Group, The University of Nottingham and DairyCo, UK.

R Core Team. 2019. R: A language and environment for statistical computing. 3.5.0 ed. R Foundation for Statistical Computing, Vienna, Austria. https://www.R-project.org/.

Rasmussen, M. D. 1995. The reduction in bacterial counts on liners by flushing with Airwash system. Internal report 58. National Institute of Animal Science, Foulum, Denmark.

Schuiling, H. J., and F. Neijenhuis. 2005. Optimal cleaning of equipment: Effectiveness of optimised teat cup cleaning in the prevention of mastitis pathogens transfer. Implications of the introduction of automatic milking on dairy farms. Report D18. Applied Research, Animal Sciences Group, Wageningen UR, Lelystad, the Netherlands

Shearn, M. F. H., J. H. Morgan, and J. E. Hillerton. 1994. Reduction of bacterial contamination of teatcup liners by an entrained wash system. Vet. Rec. 134:450-450. https://doi.org/10.1136/vr.134.17 $.450-\mathrm{a}$.

Smith, T. W., R. J. Eberhart, S. B. Spencer, E. M. Kesler, G. L. Hargrove, R. W. Wilson, and C. W. Heald. 1985. Effect of automatic backflushing on number of new intramammary infections, bacteria on teatcup liners, and milk iodine. J. Dairy Sci. 68:424-432. https: //doi.org/10.3168/jds.S0022-0302(85)80840-7.

Soejima, T., J.-I. Minami, T. Yaeshima, and K. Iwatsuki. 2012. An advanced PCR method for the specific detection of viable total coliform bacteria in pasteurized milk. Appl. Microbiol. Biotechnol. 95:485-497. https://doi.org/10.1007/s00253-012-4086-0.

Taponen, S., L. Salmikivi, H. Simojoki, M. T. Koskinen, and S. Pyorala. 2009. Real-time polymerase chain reaction-based identification of bacteria in milk samples from bovine clinical mastitis with no growth in conventional culturing. J. Dairy Sci. 92:2610-2617. https://doi.org/10.3168/jds.2008-1729.

Tenhagen, B. A., and W. Heuwieser. 2007. Cluster disinfection to reduce new intramammary infections in lactating dairy cattle. Tierarztl. Umsch. 62:364-368.

Wessels, S., and H. Ingmer. 2013. Modes of action of three disinfectant active substances: A review. Regul. Toxicol. Pharmacol. 67:456467. https://doi.org/10.1016/j.yrtph.2013.09.006.

You, H. S., S. H. Lee, Y. J. Ok, H. G. Kang, H. J. Sung, J. Y. Lee, S. S. Kang, and S. H. Hyun. 2019. Influence of swabbing solution and swab type on DNA recovery from rigid environmental surfaces. J. Microbiol. Methods 161:12-17. https://doi.org/10.1016/j.mimet .2019.04.011.

\section{ORCIDS}

Alice P. Skarbye @ https://orcid.org/0000-0001-7011-2153

Peter T. Thomsen () https://orcid.org/0000-0002-0896-1610

Mogens A. Krogh @ https://orcid.org/0000-0003-0731-6676

Line Svennesen ๑ https://orcid.org/0000-0003-3595-8713

Søren Østergaard @ https://orcid.org/0000-0002-8514-5414 